\title{
Argentine Society of Hypertension (SAHA) meeting
}

\section{Cesar A. Romero, M.D.}

\section{Post Doctoral Fellow, Renal Division \\ Emory University School of medicine \\ Atlanta, Georgia, USA \\ International Society of Hypertension \\ New investigator Committee}

On April 11-13 2019, the XXVI Argentine Society of Hypertension (SAHA) meeting took place in Mar del Plata, Argentina. Organized by Dr. Irene Ennis (organizing committee president) and Dr. Alejandro Aiello (scientific committee president) the meeting was a success with 2049 accredited delegates, and more than 75 original research work presented. International recognized speakers as well as national leaders on hypertension field gave lectures and symposiums showing the latest advances in hypertension. ISH representatives, Ernesto Schiffrin (Canada, ISH past president), Cesar Romero (USA, ISH membership committee and RAG for Americas) and Pablo Kempny (Argentina, ISH-NIC) were attending the meeting. A research course for young investigator between SAHA and ISH was presented on Thursday April 11th.

The course was attended by young investigators and physicians interested to initiates in hypertension research. On Friday 12th, an oral competition between the best 5 original works presented by young investigator was organized.

The competition was coordinated by Pablo Kempny (ISH-SAHA) and Cesar Romero (ISHSAHA) and was honored with the presence of Ernesto Schiffrin (ISH past president), Irene Ennis (current SAHA president), and James Walker (University of Leeds, UK) who were in charge of judging and selecting the awardees. Maia Aisicovich (ISIM UBA-CONICET, Argentina) won the best oral presentation with "Cardiacleptin-TRH interaction in left ventricular hypertrophy of the obese mouse", the runner up was Marina Grand (ICCS-UNICEN, Argentina) who presented "Non-invasive hemodynamic monitoring in children, adolescent and adults based on pulse contour analysis: comparative analysis with echocardiographic derived data and determination of percentile curves". We thank all the presenters and the general public who attended the oral competition.

The Argentine Meeting of Hypertension was a great opportunity to reinforcing the friendship and collaboration between the $\mathrm{ISH}$ and the SAHA.

\section{Cesar A. Romero- cromerocba@hotmail.com}

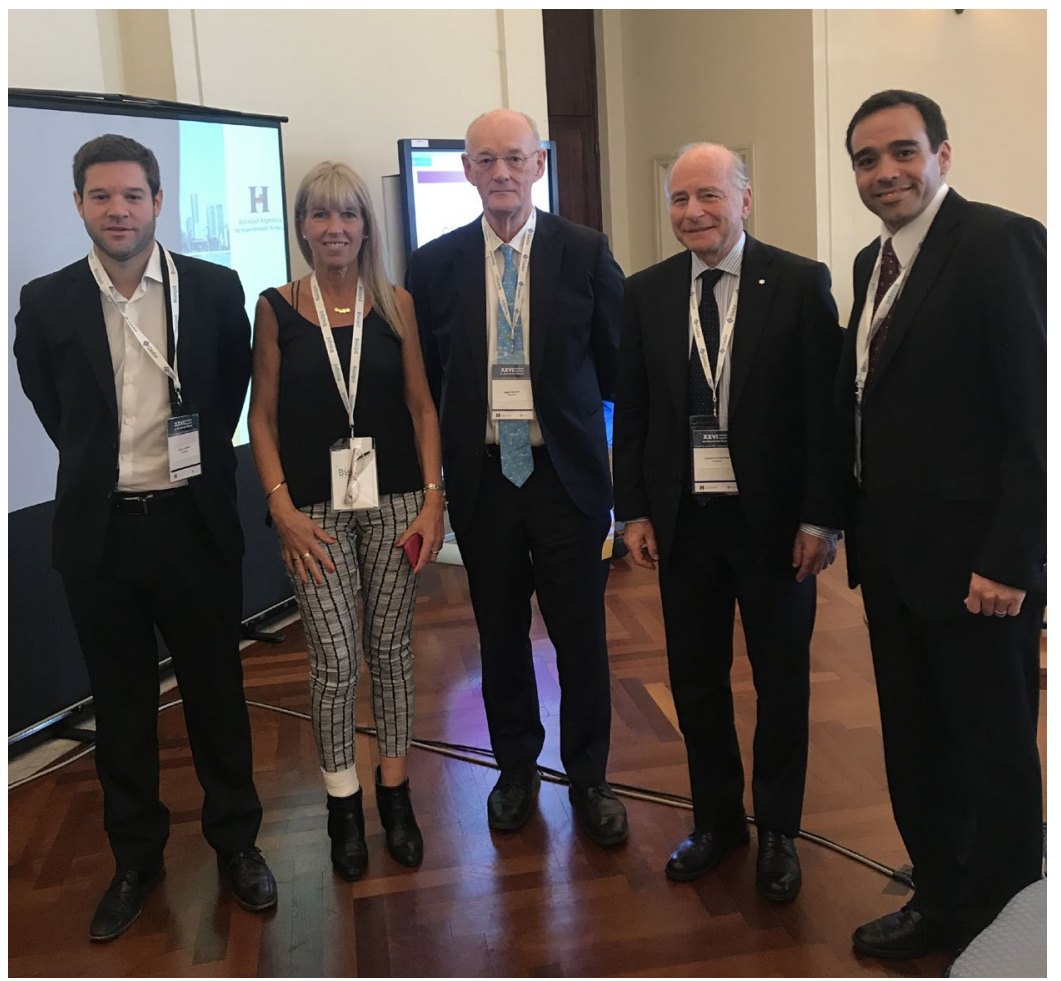

Young investigators oral competition. From left to right Pablo Kempny (Argentina, ISH-NIC), Irene Ennis (current SAHA president), James Walker (University of Leeds, UK), Ernesto Schiffrin (Canada, ISH past president) and Cesar Romero (USA, ISH membership committee and RAG for Americas). 